\title{
Luís Miguel Nava e o espaço do corpo em $O$ Céu Sob as Entranhas
}

\section{Moisés David Sousa Gomes Ferreira*}

\begin{abstract}
Resumo: O presente artigo constitui um esforço de circunscrição e exploração das principais linhas de caracterização da poesia de Luís Miguel Nava, particularmente a da tematização do corpo. Identificando o traço do fingimento analítico como uma das marcas estilísticas da produção literária do autor, interpreta-se o tratamento da corporalidade em Nava enquanto estratégia de inscrição do e no real, na busca de uma essencialidade de ser. A 'aridez' da linguagem de Nava, concretizada num rigor formal próximo de uma certa pretensão de cientificidade, é conceptualizada, a par da natureza metapoética de alguns dos seus textos, enquanto estratégia de aprofundamento da centração na corporalidade e de obtenção de uma intensificação da experiência de estar no mundo.
\end{abstract}

Palavras-chave: Luís Miguel Nava; corpo; espaço.

\begin{abstract}
The present article is an effort of circumscription and exploration of the main lines of characterization of the poetry of Luís Miguel Nava, namely the thematization of the body. Identifying the trait of analytical simulation as one of the stylistic marks of the literary production of the author, the treatment of the corporality in Nava is interpreted as a strategy of inscription of and in the real, in the search of an essentiality of being. The 'dryness' of Nava's language, materialized in a formal rigour near to a certain pretension of scientificty, is conceived, as well as the metapoetic nature of some of his texts, as a strategy of getting to the bottom of the tendency of focusing the corporality, and also as a mechanism of obtaining an intensification of the experience of being in the world.
\end{abstract}

Keywords: Luís Miguel Nava; body; space.

\section{Introdução}

Luís Miguel Nava nasceu em 1957, tendo desaparecido precocemente em 1995. A sua vida dedicou-a à construção de uma obra literária predominantemente centrada na poesia, mas também caracterizada por outras expressões, particularmente por valiosas reflexões críticas sobre literatura e arte.

O seu primeiro livro de poesia, intitulado Películas, foi publicado em 1979. Seguiramse-lhe A Inércia da Deserção (1981), Como Alguém Disse (1982), Rebentação (1984), Poemas (volume em que foram reeditados os livros anteriores, 1987), O Céu Sob as Entranhas (1989) e Vulcão (1994). A sua obra poética, acompanhada de vários textos inéditos, foi reunida no volume Poesia Completa (2002), o qual nos servirá de ponto de partida para o presente trabalho.

\footnotetext{
*Mestre em Criações Literárias Contemporâneas pela Universidade de Évora; Licenciado em Psicologia pela Universidade de Évora
} 
Considerada hoje como uma das mais fulgurantes, desconcertantes e enigmáticas vozes da poesia portuguesa da segunda metade do séc. XX, Luís Miguel Nava tem despertado nos últimos anos um interesse crescente entre os estudiosos e críticos da literatura. É nosso propósito ir ao encontro deste movimento de redescoberta de uma poesia que, provavelmente pela sua intensidade e pela diferença marcada relativamente a outros universos poéticos portugueses do mesmo período, não terá encontrado então o reconhecimento que merecia.

Depois de identificarmos as principais linhas de força da poesia do autor, faremos um breve estudo do tópico do corpo na sua obra, particularmente no livro O Céu Sob as Entranhas, socorrendo-nos de algum do pensamento de vários teóricos que se dedicam à análise da produção poética de Nava e da problemática do corpo a partir de múltiplas perspectivas.

\section{Breve caracterização do itinerário poético de Luís Miguel Nava}

A poesia de Luís Miguel Nava caracteriza-se por várias tendências peculiares. Uma delas, de acordo com Eduardo Prado Coelho (apud CANTINHO, 2002, p.1), coincide com um estilo "alucinatório", o qual, na opinião de Gastão Cruz (2002, p.293), a aproxima da escrita de um Herberto Helder ou de uma Luiza Neto Jorge. À exuberância do tecido imagético junta-se uma outra tendência, também sublinhada por Cruz (2002, p.293), que diz respeito ao cultivo da depuração e do rigor na escrita, fazendo lembrar quer o Carlos de Oliveira do 'micro-rigor' de Micropaisagem, quer o Eugénio de Andrade de Ostinato Rigore. Através deste recurso, a linguagem é capaz de atingir uma elevada concentração expressiva e um profundo despojamento. Como resultado da confluência das duas tendências apontadas, sai reforçado o carácter arrojado e inusitado das construções metafóricas de Nava, que assim se vêem dotadas de uma enorme vitalidade e dinamismo.

Ao longo do desenvolvimento do corpus poético de Luís Miguel Nava, nota-se, a par da presença dos poemas em verso, o aparecimento cada vez mais insistente de poemas em prosa. Nestes manifesta-se com particular intensidade um traço resultante da fusão das duas tendências a que fizemos menção: o carácter inusitado e exuberante do seu trabalho metafórico, e a depuração e rigor nas construções da linguagem. A este traço Cruz chama muito justamente "fingimento analítico" (2002, p.284). Tal fingimento analítico parece intensificar-se sobretudo nos últimos livros de Luís Miguel Nava, O Céu Sob as Entranhas e Vulcão, tornando-se ostensivo em textos que, sendo apresentados como poemas, acabam por assumir, como também refere Cruz (2002, p.284), traços de contos fantásticos. Estes textos, 
no dizer do mesmo autor, aproximam Luís Miguel Nava de alguma tradição literária portuguesa em que se fundem os aspectos narrativos e descritivos da prosa com uma natureza acentuadamente poética da escrita, como nos casos de Menina e Moça, de Bernardim Ribeiro, de Húmus, de Raul Brandão, do Livro do Desassossego, de Fernando Pessoa, d'Os Passos em Volta, de Herberto Helder (cf. CRUZ, 2002, p.284), e ainda, acrescentaríamos nós, de Finisterra, de Carlos de Oliveira.

Em termos temáticos, o corpo é o centro em torno do qual parece gravitar a poesia de Luís Miguel Nava (cf. CANTINHO, 2002, p.1), assumindo-se como pólo aglutinador de uma radical experiência de 'inscrição do real'. De facto, o corpo parece constituir uma espécie de matriz na qual se gravam a inquietação e o tormento com que é vivida a experiência de estar mundo, plena de contradições, dificuldades, obstáculos. Como se nesta poesia se procurasse transformar o corpo em película fotográfica (retomando o título do seu primeiro livro, Películas) que fixasse, instante após instante, o mundo fragmentado e caótico de que se faz eco, corpo mais tarde reenviado aos outros como matéria reabilitada e devolvida à sua intensidade extrema (cf. VASCONCELOS, 2005, pp.63-76). A radicalidade desta experiência pode ser percebida, e. g., através de um excerto do texto "Vitrines", incluído no livro Rebentação: "Por dentro do meu corpo, onde é possível separar do sangue os vários órgãos, a quem destes o contemple é dado vê-lo embravecer contra as vitrines. Desnudarmo-nos é pouco, há que mostrar as vísceras." (NAVA, 2002, p.143). A descida que se opera ao universo visceral será um passo recorrentemente dado no caminho que a poesia de Luís Miguel Nava percorre, caminho de procura e sondagem de um conhecimento essencial em que, pela via de um peculiar, profuso e explosivo trabalho metafórico, se diluem as fronteiras entre sentidos/razão, sensível/abstracto, sensorial/espiritual (cf. CANTINHO, 2002, p.1). Ao assumir esta concentração simbólica, o corpo, feito pura materialidade, parece, no entanto, irse revestindo progressivamente de um carácter trágico (cf. CANTINHO, 2002, p.1).

O intenso trabalho metafórico desta poesia, que conduz ao esbatimento das linhas de separação entre as categorias dicotómicas apontadas, é também visto por Fernando Pinto do Amaral como uma das particularidades da poesia de Luís Miguel Nava (2002, p.19). Este processo caracteriza-se pelo estabelecimento de uma relação de proximidade entre universos semânticos aparentemente afastados, originando efeitos por vezes desconcertantes. É sobretudo nisto que assenta o pendor alucinatório desta poesia, multiplicando-se as passagens em que se firma uma união entre objectos ou processos referentes a uma esfera material ou corpórea e outros do domínio do imaterial ou incorpóreo, como bem se nota nos seguintes trechos: "(...) as fezes imiscuindo-se no muro, a luz uma infecção que alastra pelo leite, a vara 
de agitá-lo desviada desse ofício. Estranhos actos cometia ele então, deles o mais minucioso sendo a introdução de mínimos calhaus nos intestinos." ("Olhando o Muro", Películas) (NAVA, 2002, p.51); "É como se habitasse uma cidade que tivesse um espelho por subúrbios e o mar viesse estilhaçar-se ao fundo da memória, onde se encontra o coração. Abro na página um buraco onde alicerço a casa, as letras vêm às janelas." ("Onde à Nudez", Onde à Nudez) (NAVA, 2002, p.55); "Um prego na gengiva, / bem fundo, até onde seria / de crer que só chegasse a alma, (...)" ("Bem Fundo", Vulcão) (NAVA, 2002, pp.222-223).

O discurso para o qual a poesia de Luís Miguel Nava tende é marcado pela intenção de tornar a linguagem 'árida': "Devemos, ao falar, ter o maior cuidado com as palavras que empregamos, (...) A fala quer-se árida, de uma aridez idêntica à da roupa que nos cobre o corpo ou à do céu, de que me esforço, sempre que dele falo, por deixar à mostra um dos agrafos mais profundos." ("Céu Árido", O Céu Sob as Entranhas) (NAVA, 2002, p.168). Esta aridez, atingida através da mencionada vertente 'alucinatória' e da busca de depuração, parece ser um recurso utilizado ao serviço da intensificação da experiência de captação do mundo. Se, retomando a metáfora que atrás usámos, o corpo, em Nava, pode ser olhado como uma película fotográfica (mas uma película que, através da linguagem poética, se torna definitivamente tridimensional, espessa), então a aridez que se instala na linguagem pode ser vista como uma propriedade dessa película, que a torna capaz de captar mais radicalmente as sinuosas derivas da existência humana.

A reflexão sobre a linguagem, que também se observa insistentemente em vários outros momentos da poesia de Luís Miguel Nava, configura outra dimensão importante da sua obra - uma certa vertente metapoética, também posta em evidência por AMARAL (2002, pp.20-21). O discurso metapoético pode ser observado quer em passagens de natureza mais teorética ["Escrever é, para mim, tentar desfazer nós, embora o que na realidade acabo por fazer seja embrulhar ainda mais fios. A própria caligrafia é sufocada." ("Os Nós da Escrita", Rebentação) (NAVA, 2002, p.104)], quer noutras em que vemos surgir elementos concretos ligados à escrita e ao trabalho que ela envolve, como no texto "Final", do livro Vulcão, que de seguida integralmente se transcreve:

Não foi sem dificuldades que este livro rompeu através dos interstícios do mundo até chegar às tuas mãos, leitor, para aí, como um deserto a abrir noutro deserto, criar uma irradiação simbólica, magnética, onde o branco do papel e o negro das palavras, essas cores que segundo Borges se odeiam, pudessem fundir-se e converter-se nessa outra a que, na enigmática expressão de Sá-Carneiro, a saudade se trava. Como um desses objectos cujo peso, assim que neles pegamos, instantaneamente se divide entre as nossas mãos e a alma, é mesmo de crer que ele esteja já dentro de ti - e algo de mim com ele. Acolhe-o, pois, com benevolência, que, chegada a altura, havemos de arder juntos. (NAVA, 2002, p.265) 
Outra das marcas desta poesia está associada ao problema da percepção do real. A exuberância metafórica de Nava confere à sua poesia um recorte de natureza neoexpressionista (AMARAL, 2002, p.21; CANTINHO, 2002, p.1). A aglutinação de sentidos a que se assiste nesta escrita deixa transparecer uma certa crise ontológica do sujeito, ou faz que se instale uma bruma que não permite uma clara definição do mesmo sujeito, o que se torna patente nalguns indícios de despersonalização: "Não é sequer possível saber qual de nós neste momento faz correr sobre o papel a esferográfica, de tal forma mesmo aos meus olhos ele se faz passar por mim, levando a astúcia ao ponto de se invectivar." ("O Secretário", O Céu Sob as Entranhas) (NAVA, 2002, p.157).

A partir do que até agora se disse pode compreender-se que a poesia de Luís Miguel Nava seja, no dizer de Amaral (2002, p.25), uma poesia de 'excesso' e 'violência'. O mesmo autor delimita duas áreas no âmbito das quais essas forças vão concretizar-se, nomeadamente a do erotismo e a da visceralidade do corpo e das suas entranhas (cf. AMARAL, 2002, p.25).

O eros desta poesia é claramente homossexual, o que se revela pela recorrente referência à figura do 'rapaz', sobretudo nos primeiros livros: "Há uma pedra feroz, / um rapaz, / há o olhar do rapaz atado à pedra, / o olhar do rapaz, a minha casa, / o olhar do rapaz às vezes é a pedra." ("Há Uma Pedra Feroz", Películas) (NAVA, 2002, p.39); "Este garoto é fácil compará-lo a um campo de relâmpagos / encarcerando um touro. Através da nudez vêem-se os astros." ("Através da Nudez", Películas) (NAVA, 2002, p.46).

Esta tensão erótica prolonga-se depois pelo tratamento dos motivos do corpo propriamente ditos. E o corpo, em Luís Miguel Nava, não é sobretudo o corpo experimentado enquanto veículo de expressão amorosa, ou enquanto sinal da passagem do tempo e da transitoriedade da vida, mas, como acima foi dito, o corpo vivido enquanto espaço de inscrição do real e, na sequência disso, enquanto manifestação de um fortíssimo desejo de exposição até ao âmago, até às entranhas.

Os elementos corporais dominantes na poesia de Luís Miguel Nava enquadram-se, segundo a leitura de Amaral (2002, p.28), em três categorias embriológicas distintas: (1) os órgãos de natureza endoblástica (vísceras), dos quais nenhum com insistência se individualiza; (2) os órgãos mesoblásticos (e. g., os ossos, o sangue, o coração); por fim, (3) os órgãos ectoblásticos (os nervos e a pele). Estes diversos motivos corporais estabelecem entre si complexas relações, dando origem à acentuação de um antagonismo profundo/superficial que talvez seja vencido apenas pela experiência redentora da paixão "É sem dúvida em dias de maior / paixão que pelo coração se chega à pele." («Paixão», Rebentação) (NAVA, 2002, p.124). 
Uma vez encontradas as principais linhas de força da poesia de Luís Miguel Nava, tentar-se-á agora perceber de que significados se reveste este tão peculiar aprofundamento da vivência corporal, em particular no livro O Céu Sob as Entranhas.

\section{A densidade do corpo em $O$ Céu Sob as Entranhas}

Passar-se-á agora a uma análise mais detalhada de como se efectiva a vivência corporal na poesia de Luís Miguel Nava, tendo por base o livro O Céu Sob as Entranhas, aquele em que mais insistentemente - e logo no título do próprio livro isso se evidencia - esta dimensão é tocada e poeticamente trabalhada.

Para a nossa análise partiremos de várias pistas de interpretação propostas por Amaral e Cruz. Amaral coloca a hipótese de toda a atracção que o corpo e os seus órgãos exercem sobre Nava se dever a uma certa "dimensão cósmica" envolvida no caminho de descida aos meandros da carne, em que o mesmo autor vê um mergulho nas "raízes do ser" (cf. AMARAL, 2002, p.27). Por outro lado, Cruz propõe que se olhe o corpo na poesia de Luís Miguel Nava como "o lugar totalizante da existência" (CRUZ, 1999a, p.187), e também que se leia a sua poesia como uma evolução "no sentido de um cada vez maior aprofundamento da essencialidade da vida" (CRUZ, 1999b, p.192).

Estas propostas de leitura, que nos parecem merecer toda a atenção, incidem sobre a ideia de que o corpo, em Nava, funciona como uma espécie de núcleo para o qual conflui a densidade de todas as experiências existenciais. É nesse núcleo que simbolicamente se ensaia e dramatiza a demanda do ser que procura aprofundar-se e clarificar-se.

Será, então, lícito afirmar que se assiste, na poesia de Luís Miguel Nava, a um movimento de 'cosmificação' do corpo, em dois sentidos. Em primeiro lugar, o corpo assume propriedades pertencentes a outras esferas da realidade que não a da materialidade. Observase como que uma expansão do corpo: nesta poesia, a materialidade do corpo torna-se lugar de expressão de vários outros níveis do real - afectivo e emocional (nível psicológico, subjectivo), social (nível intersubjectivo) e espiritual (nível a que atribuímos a designação de metassubjectivo). Este processo tem como consequência a intensificação das vivências subjectivas sugeridas pelo discurso do sujeito poético, uma vez que as confina a um estreito feixe de horizontes (como se se reduzisse toda a experiência do mundo a um pequeno ponto de infinita densidade), e também a radicalização dos processos dramatizados no palco da materialidade. Luís Miguel Nava constrói assim um universo aparentemente fechado, no qual, por se projectarem num só plano de realidade fenómenos que, na experiência corrente do 
mundo, habitualmente se projectam em mais do que um plano, se opera uma revalorização desses mesmos fenómenos. Readquirem, por este processo, o seu valor original, ao serem encenados longe do tecido do quotidiano e do senso comum. São como que devolvidos ao seu 'excesso', à sua condição 'sublime'. A estética do sublime é também justamente apontada por Vasconcelos (2005, p.71) como um dos traços marcantes da escrita de Nava.

Em segundo lugar, paralelamente a este processo de expansão - o corpo a estender-se, a crescer, como se quisesse albergar em si todo o universo possível -, há um movimento de contracção do corpo. Ao mesmo tempo que se amplia para tudo em si reunir, contrai-se, como se nada senão ele e o seu dinamismo existisse. Mas esta é a contracção de um corpo que tudo contém. Tal é o segundo sentido que se atribui ao movimento de cosmificação do corpo neste passo, o corpo individualiza-se, torna-se de novo singular, confina-se uma vez mais ao seu espaço delimitado, revelando-se como um microcosmos que reflecte os acontecimentos «macrocósmicos» (das outras esferas da realidade). O corpo é aqui um espelho absoluto - no corpo tudo acontece, tudo se encena. Tomando emprestado da física de Stephen Hawking o conceito de 'singularidade' - "ponto em que a curvatura do espaço-tempo é infinita" (HAWKING, 2002, p.207) -, parece legítimo afirmar-se que, neste passo, o corpo se converte numa singularidade - a experiência de tudo (que decorre no espaço e no tempo) confina-se a um ponto de infinita densidade espaciotemporal e de tamanho nulo que imita, reproduz e resume o ponto a partir do qual o Universo se terá formado.

Em síntese, pode dizer-se que o primeiro sentido conferido a este processo de cosmificação consiste na projecção dos fenómenos que ocorrem em vários níveis de realidade num só nível de realidade - o da materialidade. Tudo se encontra na materialidade. O segundo sentido desta cosmificação é exactamente o oposto do primeiro - a materialidade encontra-se, e ao seu significado, em tudo. Agora, os outros níveis de realidade já não são projectados num só, mas desdobram-se uns nos outros, encontram-se uns nos outros e uns nos outros se resumem.

Ao primeiro sentido do processo de cosmificação atribuir-se-á a designação de 'cosmificação expansiva'; ao segundo sentido, a de 'cosmificação singularizante'.

Procurar-se-á agora encontrar alguns exemplos que no livro $O$ Céu Sob as Entranhas ilustrem tais processos de cosmificação expansiva e cosmificação singularizante.

A cosmificação expansiva pode ser notada em passagens como: "Os meus ossos estão espetados no deserto, não há um só no meu corpo que lhe escape. (...) O vento apoderou-seme das vértebras. O próprio sol que entre elas brilha é descarnado, um sol deserto, onde o deserto penetrou." ("Estacas", O Céu Sob as Entranhas) (NAVA, 2002, p.160); "A pele por 
fulgurantes / instantes muitas vezes abre-se até onde / seria impensável que exercesse / com tão grande rigor o seu domínio." ("Paisagem Citadina", O Céu Sob as Entranhas) (NAVA, 2002, p.161); "Ao unir-se assim às mais variadas épocas, a pele vai aos poucos adquirindo a configuração dum polvo, o qual, como se sabe, é de todos os animais o que mais se assemelha a uma raiz." ("O Polvo", O Céu Sob as Entranhas) (NAVA, 2002, p.172). Também no texto "O Corpo Espacejado", do mesmo livro, se encontra bem patente o processo de cosmificação expansiva:

Perdia-se-lhe o corpo no deserto, que dentro dele aos poucos conquistava um espaço cada vez maior, novos contornos, novas posições, e lhe envolvia os órgãos que, isolados nas areias, adquiriam uma reverberação particular. Ia-se de dia para dia espacejando. (...) A sua carne exercia aliás uma enigmática atracção sobre as estrelas, que em breve conseguiu assimilar, exibindo-as, aos olhos de quem o não soubesse, como luminosas cicatrizes cujo brilho, transmutado em sangue, lentamente se esvaía. (NAVA, 2002, p.166)

No que diz respeito à cosmificação singularizante, é visível em passagens como as seguintes: "Em certas posições, vêem-se as cordas / do nosso espírito esticadas num terraço. // A roupa dói-nos porque, embora / nos cubra a pele, é dentro / do espírito que estão os tecidos amarrados." ("Paisagem Citadina", O Céu Sob as Entranhas) (NAVA, 2002, p.161); "Um dia, ao acordar, deu por ter deixado todos os seus ossos num dos sonhos, do qual, como num espelho, a carne e a roupa juntas irrompiam. Nunca mais desde então os pôde espetar na realidade, coisa que antes tanto se orgulhava de fazer." ("Os Ossos", O Céu Sob as Entranhas) (NAVA, 2002, p.173); "A nossa anatomia é uma terra enigmática e longínqua sobre cujo mapa jamais pensámos debruçar-nos." ("A Cor dos Ossos", O Céu Sob as Entranhas) (NAVA, 2002, p.174). No mesmo texto, pode ler-se ainda a passagem que se segue, também ilustrativa do processo de cosmificação singularizante:

Um outro passo a dar nos meandros deste raciocínio é o que nos leva a pôr a hipótese de os ossos se poderem refugiar, em certos casos, na memória, como se esta os absorvesse e quem por eles fosse constituído então se invertebrasse ou reduzisse a um mero filamento onde assentasse a carapaça da memória, no interior da qual o corpo inteiro se engolfasse até completamente se sumir. (NAVA, 2002, p.175)

Os processos de cosmificação expansiva e de cosmificação singularizante podem ser lidos como mecanismos através dos quais se procura concretizar o acesso a uma essencialidade da vida e do ser. Ora, o acesso a esta essencialidade mais não é do que um avanço na direcção de um território de definição de uma identidade que se oponha ao vazio instalado no ser na sequência de uma experiência de estar no mundo em que tomam a dianteira os fenómenos de alienação do próprio ser. Este vazio é frequentemente sugerido em O Céu Sob as Entranhas: "Naquilo a que chamamos eu há sempre um espaço inocupado, 
onde parece alimentar-se um mecanismo que de dentro de nós próprios se apostasse em escorraçar-nos, repelir-nos, algo cuja natureza nos é estranha e que não raro ocupa toda a nossa identidade." ("O Último Reduto", O Céu Sob as Entranhas) (NAVA, 2002, p.171); "Destapo uma vez mais o ralo. Assim corre a amizade - penso, olhando o redemoinho -, assim correm os afectos, que, depois de encherem a bacia onde a custo nos lavamos sem os fazermos transbordar, se escoam sem regresso em direcção ao caos." ("Lembrança de A. Morin", O Céu Sob as Entranhas) (NAVA, 2002, p.203).

Finalmente, noutros pontos desta poesia transita-se do vácuo, lugar sem saída, em que o excesso convocado para a materialidade do corpo não deixa espaço para que a vida subsista (diríamos nós que isto se dá quando o processo de cosmificação expansiva não é acompanhado pelo processo de cosmificação singularizante), para um outro lugar em que, se não se acede à comunhão plena com uma identidade totalizadora, pelo menos claramente se regista a nostalgia dessa mesma identidade: "Ignoro o que ao certo seja ser, mas, seja o que for, dispõe de intensidade própria e regulável como o som dum aparelho ou a velocidade dum motor. Há momentos em que 'sou' mais do que noutros, em que, se assim pode dizer-se, tenho a minha identidade acelerada." ("Identidade", O Céu Sob as Entranhas) (NAVA, 2002, p.180). No texto "Matadouro" é ainda mais evidente este movimento:

\begin{abstract}
Dancei num matadouro, como se o sangue de todos os animais que à minha volta pendiam degolados fosse o meu. Dancei até que em mim houvesse espaço para um poema de que todas as imagens depois fossem desertando. (...) Só num espelho assim saído há pouco das entranhas dum ser vivo se desenha a nossa verdadeira imagem, ao invés da frigorífica mentira onde é comum a vermos esboçar-se. Só esse espelho capta a espessa luz em que parecem ter-se consumido os próprios astros, essa luz que com os objectos que ilumina se confunde numa única substância capaz de arrancar-nos à treva e de dar cor à santidade. (...) A luz que das vísceras emana é a de deus, aquela que, por uma excessiva dose de trevas misturada, mais que qualquer outra se aproxima da de deus, que resplandece nas carcaças em costelas onde é fácil pressentir as incipientes asas de algum anjo. $\mathrm{O}$ berro do animal que qualquer faca anónima remete à condição daqueles cujo sangue se escoe ao nosso lado é o único som a que dançar merece a pena. (NAVA, 2002, pp.181-182)
\end{abstract}

Particularmente através deste belíssimo poema em prosa (do qual se cita, por tanta se considerar ser a sua importância neste livro, uma extensa parte), observa-se que a percepção de uma identidade totalizadora se dá através da mediação da morte. Os corpos mortos dos animais, e, mais do que eles, o próprio instante da sua morte, convocam e libertam para o espaço da existência a desmedida intensidade da sua vida - vida que, afinal, é finita, e com a morte se perde. É nesse desmedida intensidade vital que o próprio sujeito poético procura inscrever-se, fixar-se, compreendendo-se assim que diga (ou cante...) "Dancei num matadouro, como se o sangue de todos os animais que à minha volta pendiam degolados fosse o meu.", ou "A luz que das vísceras emana é a de deus, (...)" (NAVA, 2002, p.181) 
Toda esta imagem faz recordar o conceito de «corpo-sem-órgãos», que remonta à filosofia de Gilles Deleuze e Felix Guattari, e ao qual José Gil (GIL, 1997) dedica a sua atenção. No poema "Matadouro", o sujeito poético assimila o seu corpo ao dos cadáveres dos animais esventrados no próprio matadouro, dançando e experimentando no seu próprio corpo a presença do sangue dos animais mortos. Ora, a noção de corpo-sem-órgãos remete para a ideia do corpo como "poder de transformação e devir - devir sensitivo, afectivo, que atinge e desorganiza a unidade da consciência." (GIL, p.185). O corpo, neste poema, parece constituirse como o veículo do desejo de um devir, de uma transformação, do acesso a uma identidade totalizadora, que desorganiza a consciência (e daí a feição efectivamente dionisíaca do festim encenado em "Matadouro"), mas tende a derramá-la não numa inconsciência, mas numa supraconsciência (para a qual remete a presença do «deus»).

Este processo de devir pode, sem prejuízo, aproximar-se da noção de individuação presente na psicologia de Carl Jung. A individuação é definida como o "processo psicológico que conduz, tendencialmente, cada ser humano para a realização consciente e plenamente cumprida de si próprio como um ser único." (PROENÇA, 2003, p.27). O processo de individuação tende a levar o sujeito à experiência de um centro psíquico diferente do ego, a que Jung chama 'Si Mesmo'. O Si Mesmo é, por sua vez, conceptualizado como "o centro e a totalidade da psique, capaz de conciliar todos os opostos." (PROENÇA, 2003, p.28).

Na poesia de Luís Miguel Nava, o culminar de todo o processo de procura de inscrição do sujeito numa identidade totalizadora ocorre precisamente com a intensa manifestação vital de que o poema "Matadouro" é eloquente exemplo.

O corpo, a sua materialidade, e o modo como se tratam e exprimem particularmente em $O$ Céu Sob as Entranhas (mas também nos restantes livros de Luís Miguel Nava), acabam então por poder ser olhados como a encarnação da nostalgia dessa identidade totalizadora, passível de ser conceptualizada na proximidade do que para Carl Jung é o centro psíquico do Si Mesmo, portador do potencial de vida que pode preencher o quase irremediável vazio que tolhe o ser quando a fixação egóica é levada aos seus limites e entra em ruptura. O corpo, olhado desta perspectiva, poderá legitimamente designar-se por 'corpo derradeiro'.

\section{Conclusão}

Propõe-se, enfim, que o corpo, em Luís Miguel Nava, seja um corpo que se metamorfoseia, no mesmo poema e de poema para poema; um corpo que se derrama em planos que não o da materialidade e os converte nela; um corpo que se contrai e percebe como 
contentor de todos os outros planos do real; um corpo, finalmente, que se rasga e se abre à luz como nostalgia do achamento de uma identidade englobante que desenhe no firmamento do ser a possibilidade de ultrapassar o fechamento existencial a que se vê confinado quando é posta em marcha a reificação da vida num núcleo identitário rígido e débil.

A linguagem poética - linguagem profundamente vivida e, por conseguinte, levada ao limite das suas possibilidades -, afirma-se então como cenário e veículo de uma redenção, da procura de uma identidade nova, mais flexível, e, na sua condição de espaço humano que mais amplas possibilidades de autoconfiguração alberga, como primeiro e último dos espaços. É, deveras, a casa do ser, na terminologia de Martin Heidegger. A linguagem poética é um meio que permite que a existência adquira espessura - um corpo, o corpo que tende para o 'corpo derradeiro'. E se viver é ser num corpo, é ser um corpo (esse 'corpo derradeiro', em que todos os planos de realidade se querem e encontram já integrados e harmonizados), então viver é ser poeta.

\section{Referências}

AMARAL, Fernando Pinto do. As Cicatrizes da Lava (Prefácio). In NAVA, Luís Miguel. Poesia Completa (1979 - 1994). Lisboa: D. Quixote, 2002. p.19-31.

CANTINHO, Maria João. (2002). Luís Miguel Nava: o corpo como inscrição do real ou o corpo radical. Revista Agulha, Fortaleza, São Paulo, n. ${ }^{\circ}$ 25. Disponível em: http://www.revista.agulha.nom.br/ag25nava.htm. Acesso em 7 de Janeiro de 2009.

CRUZ, Gastão. Luís Miguel Nava: O Corpo Vulnerável. In CRUZ, Gastão. A Poesia Portuguesa Hoje. Lisboa: Relógio D'Água, 1999a. p.186-188.

CRUZ, Gastão. Luís Miguel Nava - Clarões, Deflagrações, Rebentações. In CRUZ, Gastão. A Poesia Portuguesa Hoje. Lisboa: Relógio D'Água, 1999b. p.191-193.

CRUZ, Gastão. Dos Relâmpagos às Trevas na Poesia de Luís Miguel Nava (Posfácio). In NAVA, Luís Miguel. Poesia Completa (1979 - 1994). Lisboa: D. Quixote, 2002. p.281290.

NAVA, Luís Miguel. Poesia Completa (1979 - 1994). Lisboa: D. Quixote, 2002.

PROENÇA, Carminda (2003). Sincronicidade e Individuação em Jung. In SIMÕES, Mário, RESENDE, Mário, \& GONÇALVES, Sandra (Coords.) Psicologia da Consciência: Pesquisa e Reflexão em Psicologia Transpessoal. Lisboa: Lidel, 2003. p.27-43.

GIL, José. Metamorfoses do Corpo. Lisboa: Relógio D'Água, 1997.

HAWKING, Stephen. O Universo Numa Casca de Noz. Lisboa: Gradiva, 2002. 
VASCONCELOS, Ricardo (2005). Fixar o Olhar. Relâmpago, n. ${ }^{\circ}$ 16, pp.63-76, Abril, 2005. 